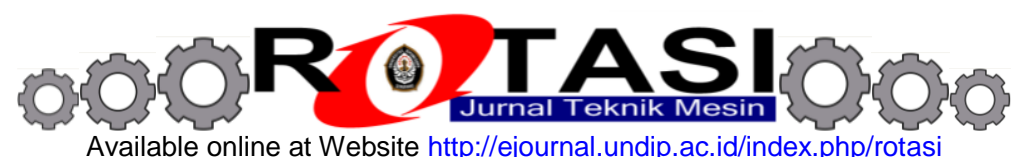

\title{
SIMULASI BALISTIK PLAT BAJA UNTUK KENDARAAN MILITER PENDOBRAK DENGAN PELURU MU4-TJ MENGGUNAKAN METODE ELEMEN HINGGA
}

\author{
*Rifky Ismail, Yogi Reza Ramadan \\ Departemen Teknik Mesin, Fakultas Teknik, Universitas Diponegoro \\ Jalan Prof. H. Soedarto, SH. Tembalang, Semarang \\ *E-mail: ismail.rifky@gmail.com
}

\begin{abstract}
ABSTRAK
Indonesia telah berhasil memproduksi kendaraan tempur yang diakui oleh dunia internasional. Kendaraan yang diberi nama Anoa dan Komodo ini dikategorikan sebagai Battering Ram atau Kendaraan Pendobrak. Jenis ini digunakan untuk pertempuran khusus dan aktivitas anti teror. Kendaraan pendobrak ini mampu menabrak beton setebal $30 \mathrm{~cm}$ dan dikendarai saat gelap karena menggunakan sistem kamera night vision. Kendaraan ini juga dilengkapi dengan peralatan elektronik dan komunikasi canggih mendukung operasi khusus. Penelitian ini fokus pada kendaraan Komodo dengan plat baja penyusun setebal $4 \mathrm{~mm}$. Pelat baja ini telah mengalami uji tembak eksperimental untuk mengetahui karakteristik balistik dari material. Hasilnya didapatkan bahwa pada pengujian balistik plat baja tersebut diketahui bahwa ketebalan $8 \mathrm{~mm}$ dari plat baja ini tidak sampai tertembus peluru tajam pada sudut tembak $90^{\circ}$. Hanya satu jenis peluru yang digunakan dalam uji eksperimen plat tersebut. Diperlukan kajian tambahan yaitu analisa balistik pada plat baja penyusun kendaraan Komodo Pendobrak menggunakan metode elemen hingga dengan jenis peluru yang lain. Kajian dilakukan dengan software ABAQUS pada sudut tembak paling kritis $90^{\circ}$ dan peluru baru yaitu MU4TJ. Hasil analisa tersebut adalah peluru dapat menembus plat baja $4 \mathrm{~mm} 10 \mathrm{~m}$ dengan peluru MU4-TJ. Penggunaan plat baja $4 \mathrm{~mm}$ tidak disarankan untuk plat Komodo, namun bila tetap dikehendaki untuk digunakan sebaiknya dilakukan penambahan perlakuan material yaitu surface hardening.
\end{abstract}

Kata kunci: ABAQUS, elemen hingga, kajian balistik, kendaraan pendobrak, plat baja

\section{PENDAHULUAN}

PT. Pindad, Indonesia, selaku produsen peralatan militer dalam negeri telah menghasilkan kendaraan tempur yang diakui dunia internasional, yaitu Anoa 6 x 6 dan Komodo 4 x 4. Kendaraan ini tidak hanya digunakan oleh TNI pada misi di dalam negeri dan di luar negeri seperti pada pengiriman pasukan perdamaian di Libanon dan Kongo tahun 2010 [1] sebagaimana terlihat pada Gambar 1 tetapi kendaraan militer ini juga telah diekspor ke beberapa negara lain [1]. kendaraan ini didesain, dirakit dan diproduksi di dalam negeri oleh para bumiputra, staf BUMN PT. Pindad.
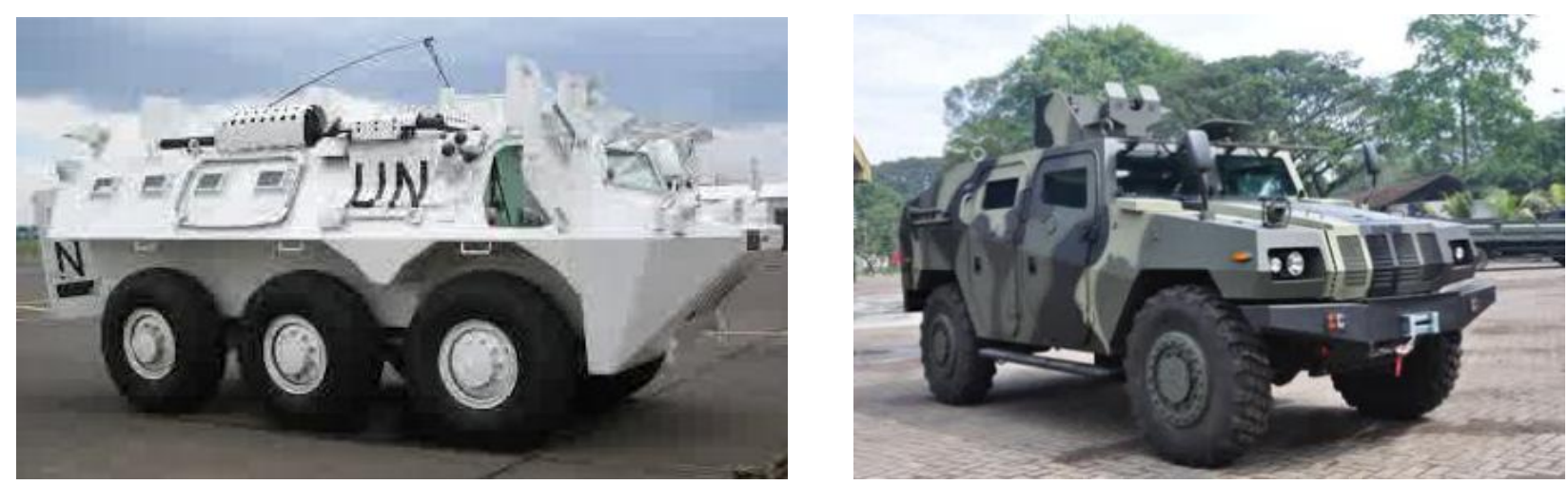

Gambar 1. Produk Anoa 6 x 6 yang sedang berdinas dalam misi perdamaian dan Komodo 4 x 4 produk pindad yang digunakan TNI [1].

Pada penelitian ini, fokus diberikan pada mobil tempur versi ringan yang bernama Komodo 4 x 4 . Desain dan konsep kendaraan Komodo ini mengacu pada mobil perang ringan jenis Humvee buatan Amerika Serikat dan Sherpa buatan Prancis. Kendaraan ini dikategorikan sebagai Battering Ram atau Kendaraan Pendobrak. Jenis ini digunakan untuk pertempuran khusus dan aktivitas anti teror. Kendaraan pendobrak ini mampu menabrak beton setebal $30 \mathrm{~cm}$ dan dikendarai saat gelap karena menggunakan sistem kamera night vision. Kendaraan ini juga dilengkapi dengan peralatan elektronik dan komunikasi canggih mendukung operasi khusus. Komodo difungsikan sebagai kendaraan taktis yang mampu menempuh segala medan berat baik itu jalan berlumpur, berpasir, serta bergunung-gunung. Hal itu ditunjang dengan kemampuan komodo yang dapat menerjang tanjakan $31^{\circ}$ dan kemiringan sisi samping $17^{\circ}$. Dalam pengembangan kendaraan pendorbak ini terdapat beberapa kajian penelitian yang diperlukan. Salah satunya adalah 
kajian balistik terhadap plat baja penyusun kendaraan Komodo Pendobrak menggunakan metode elemen hingga. Pelat baja ini telah mengalami uji tembak eksperimental untuk mengetahui karakteristik balistik dari material. Hasilnya didapatkan bahwa pada pengujian balistik plat baja tersebut diketahui bahwa ketebalan 8 mm dari plat baja ini tidak sampai tertembus peluru tajam pada sudut tembak $90^{\circ}$. Hanya satu jenis peluru yang digunakan dalam uji eksperimen plat tersebut. Adanya kajian simulasi numerik menggunakan metode elemen hingga dengan variasi jenis peluru yang lain perlu dilakukan untuk mengamati dampak perubahan jenis peluru terhadap perilaku balistik plat yang akan digunakan. Hasil simulasi penelitian nantinya dapat digunakan untuk beberapa penelitian lanjutan.

Berbagai penelitian mengenai uji balistik untuk menguji kekuatan suatu plat atau bahan pelindung lainnya sudah banyak dilakukan oleh para peneliti baik dalam maupun luar negeri. Seperti Flores-Johnson, Saleh dan Edwards. Mereka bertiga menguji performansi balistik pada multi-layered plates dengan menggunakan peluru berukuran $7.62-$ mm. Dalam pengujian ini Flores dkk menggunakan 2 material sebagai pembanding yaitu Weldox $700 E$ dan AL 7075 T651seperti ditunjukkan pada Gambar 2. Dari pengujiaan tersebut didapatkan bahwa perbedaan performansi antara monolithic dan double-layered plates tidak terlalu signifikan untuk Weldox 700E. Sedangkan untuk plat AL-7075-T651, untuk ketebalan kurang dari $20 \mathrm{~mm}$ tidak menunjukkan perbedaan yang signifikan pula, namun untuk ketebalan diatas 30mm memimiliki perbedaan performan yang sangat besar [2].

Penelitian lainnya juga dilakukan oleh Vit Shanel dan Miroslav Spaniel. Mereka berdua meneliti mengenai efek impak dari uji balistik terhadap pelindung dengan struktur berlapis (sandwich) yang dapat dilihat pada Gambar 3. Pada peneleitian tersebut menggunakan armor berjenis ARMOX 500T yang di produksi oleh perusahaan Swedia, SSAB $\mathrm{AB}$ dengan ketebalan $3.5 \mathrm{~mm}$. Untuk referensi amunisi yang digunakan adalah jenis .233 Remington yang biasa digunakan oleh senjata tipe FMJ (M193). Dari penelitian tersebut Shanel dan Spaniel berhasil melakukan validasi antara pengujian eksperimental dengan pengujian FEM. Sehingga permodelan ini dapat digunakan untuk variasi lainnya dengan material - material yang berbeda [3]
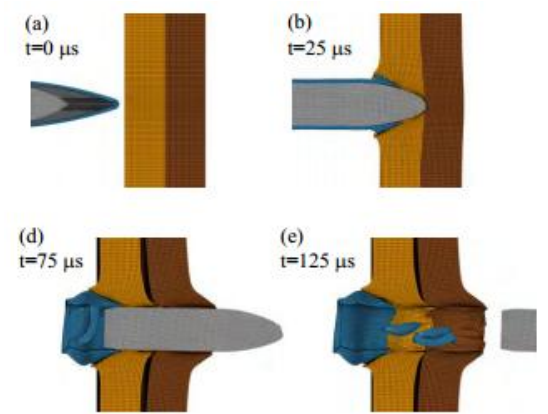

(a)
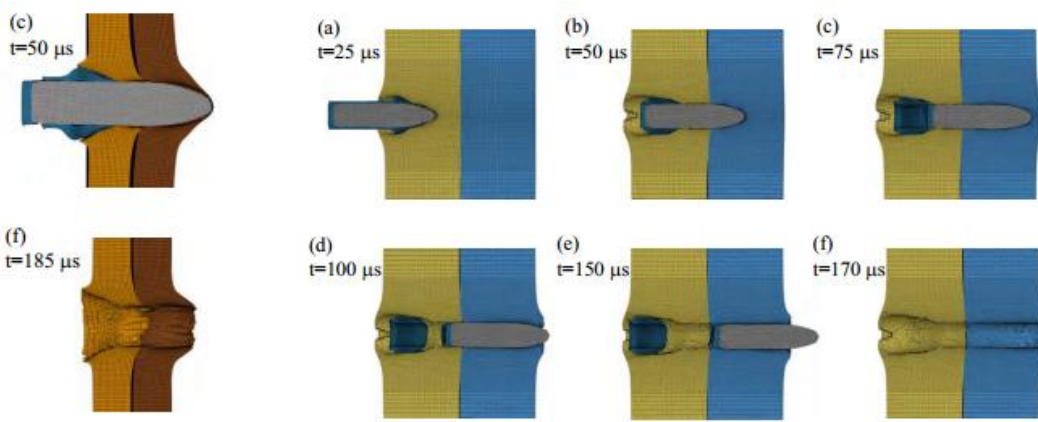

(b)

Gambar 2. (a) Penetrasi pada plat Weldox $700 E$ pada kecepatan $679 \mathrm{~m} / \mathrm{s}$ dan (b) Penetrasi pada plat $A L$ 7075-T651 pada kecepatan $934 \mathrm{~m} / \mathrm{s}$ [2].

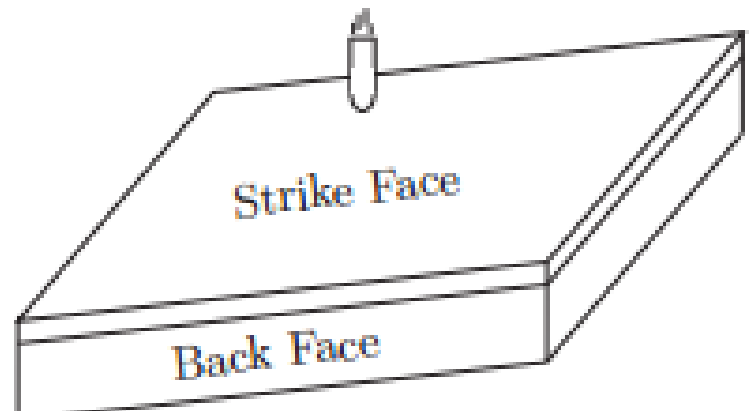

Gambar 3. Permodelan sandwich armor [3].

\section{MATERIAL DAN METODOLOGI}

\subsection{MATERIAL}

Pada simulasi uji tembak yang dilakukan, senjata yang digunakan adalah SS dengan peluru MU4-TJ dengan jarak tembak $10 \mathrm{~m}$. Gambar 4 menunjukkan jenis-jenis munisi atau peluru yang sering digunakan dalam dunia militer. Pada kajian eksperimen, peluru yang digunakan adalah MU4-TJ. Dalam pemodelan, material peluru yang digunakan material munisi yang digunakan adalah Antimony dilapis Brass 90 (CuZn10) sebagaimana terlihat pada Tabel 1 dan 2. 


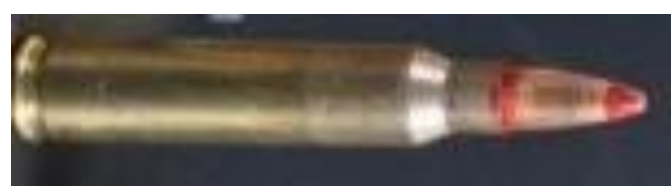

Gambar 4. Peluru atau munisi yang digunakan dalam simulasi elemen hingga dalam penelitian ini MU4-TJ [4].

Tabel 1. Tabel spesifikasi Antimony [4]

\begin{tabular}{cc}
\hline Spesifikasi & Nilai \\
\hline Ultimate tensile strength (min.) & $520 \mathrm{MPa}$ \\
Thermal Conductivity & $27.0 \mathrm{~W} / \mathrm{m}-\mathrm{K}$ \\
Elastic Modulus & $55 \mathrm{GPa}$ \\
Shear Modulus & $20 \mathrm{GPa}$ \\
Mass Density & $1066 \mathrm{~kg} / \mathrm{m}^{3}$ \\
Hardness, Brinell & 15.4 \\
\hline
\end{tabular}

Tabel 2. Tabel spesifikasi Brass 90 (CuZn10) [5] (Pindad, 2015).

\begin{tabular}{cc}
\hline Spesifikasi & Nilai \\
\hline Ultimate tensile strength (min.) & $469 \mathrm{MPa}$ \\
Yield Strength (min.) & $240 \mathrm{MPa}$ \\
Elastic Modulus & $97 \mathrm{GPa}$ \\
Shear Modulus & $37 \mathrm{GPa}$ \\
Mass Density & $8490 \mathrm{~kg} / \mathrm{m}^{3}$ \\
Poisson's Ratio & 0.31 \\
\hline
\end{tabular}

Material dari plat baja penyusun body Komodo 4x4 Pendobrak adalah HB 500 dengan spesifikasi yang terlihat pada Tabel 3.

Tabel 3. Spesifikasi material plat HB 500 [5] (Pindad, 2015)

\begin{tabular}{cc}
\hline Spesifikasi & Nilai \\
\hline Tensile Strength & $1640 \mathrm{MPa}$ \\
Yield Strength (min.) & $470 \mathrm{MPa}$ \\
Elongation in $50 \mathrm{~mm} \mathrm{G.} \mathrm{L}$ & $10 \%$ \\
$+20^{\circ}$ C $(10 \mathrm{~mm} \times 10 \mathrm{~mm})$ & $35 \mathrm{~J}$ \\
Hardness & $477-534 \mathrm{HB}(500 \mathrm{HB})$ \\
Mass Density & $2700 \mathrm{~kg} / \mathrm{m}^{3}$ \\
Poisson's Ratio & 0.33
\end{tabular}

\subsection{METODOLOGI}

Gambar 5 merupakan diagram alir metodologi penelitian. Tahapan simulasi dimulai dengan menggambar $C A D$ (computer aided design) atau gambar benda kerja menggunakan software Solidworks 2015. Penggambaran CAD dibutuhkan untuk melakukan proses drawing bagian-bagian plat dan peluru. Hasil dari pemodelan CAD akan diekspor 
ke dalam software metode elemen hingga yang dalam penelitian ini akan menggunakan software ABAQUS 6.11. Setelah proses drawing selesai dan hasil drawing diekspor ke software Abaqus 6.11, proses penyesuaian gambar plat sesuai dimensi diatur dengan skala 1:1. Dimensi plat yang digunakan adalah $100 \mathrm{~mm}$ x $100 \mathrm{~mm}$ dengan ketebalan 4 $\mathrm{mm}$.

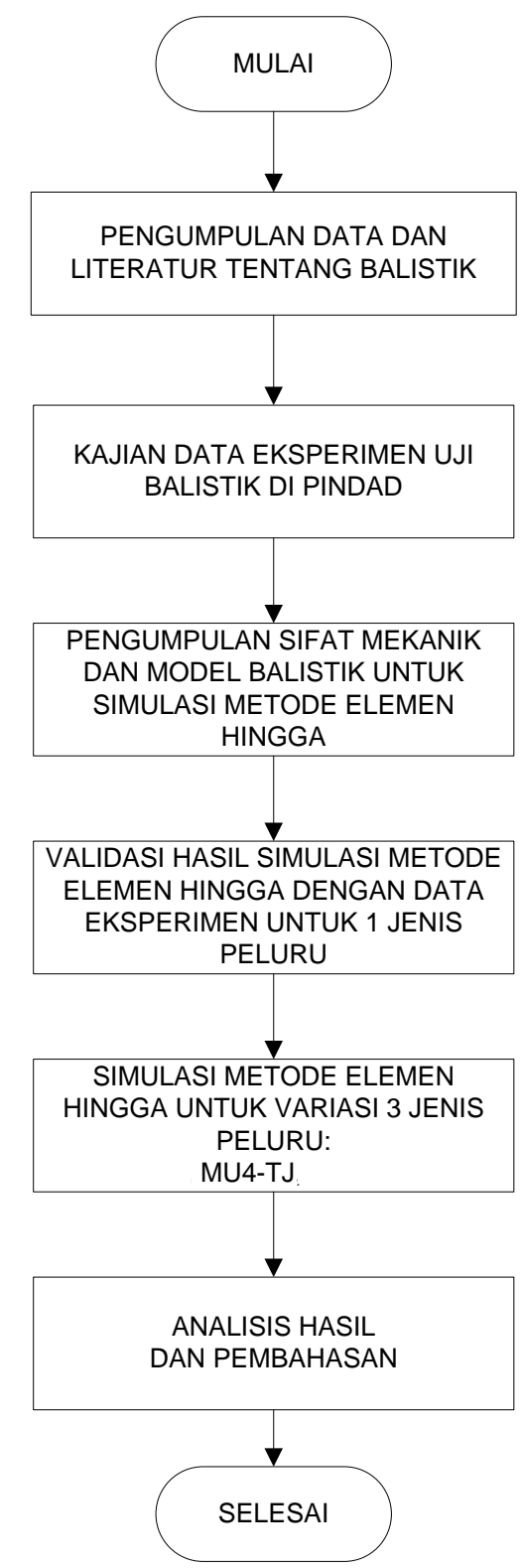

Gambar 5. Diagram alir penelitian.

Langkah selanjutnya yaitu pembuatan geometri peluru yang dilakukan dengan software CAD. Gambar 6 menunjukkan dimensi geometri peluru.

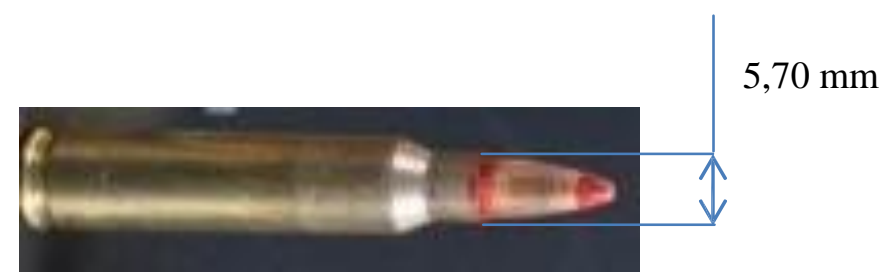

Gambar 6. Geometri peluru MU4-TJ.

Proses simulasi impact menggunakan metode elemen hingga dilakukan di software ABAQUS 6.11 karena adanya kelebihan large plastic deformation dan impact simulation yang dimiliki software ini. Proses simulasi selalu dimulai dengan assembly kedua part tersebut kemudian mengatur parameter yang diperlukan untuk analisis. Langkah 
selanjutnya klik kanan pada job kemudian pilih submit. Gambar 7 menunjukkan sebagian proses simulasi yang dilakukan di ABAQUS 6.11.

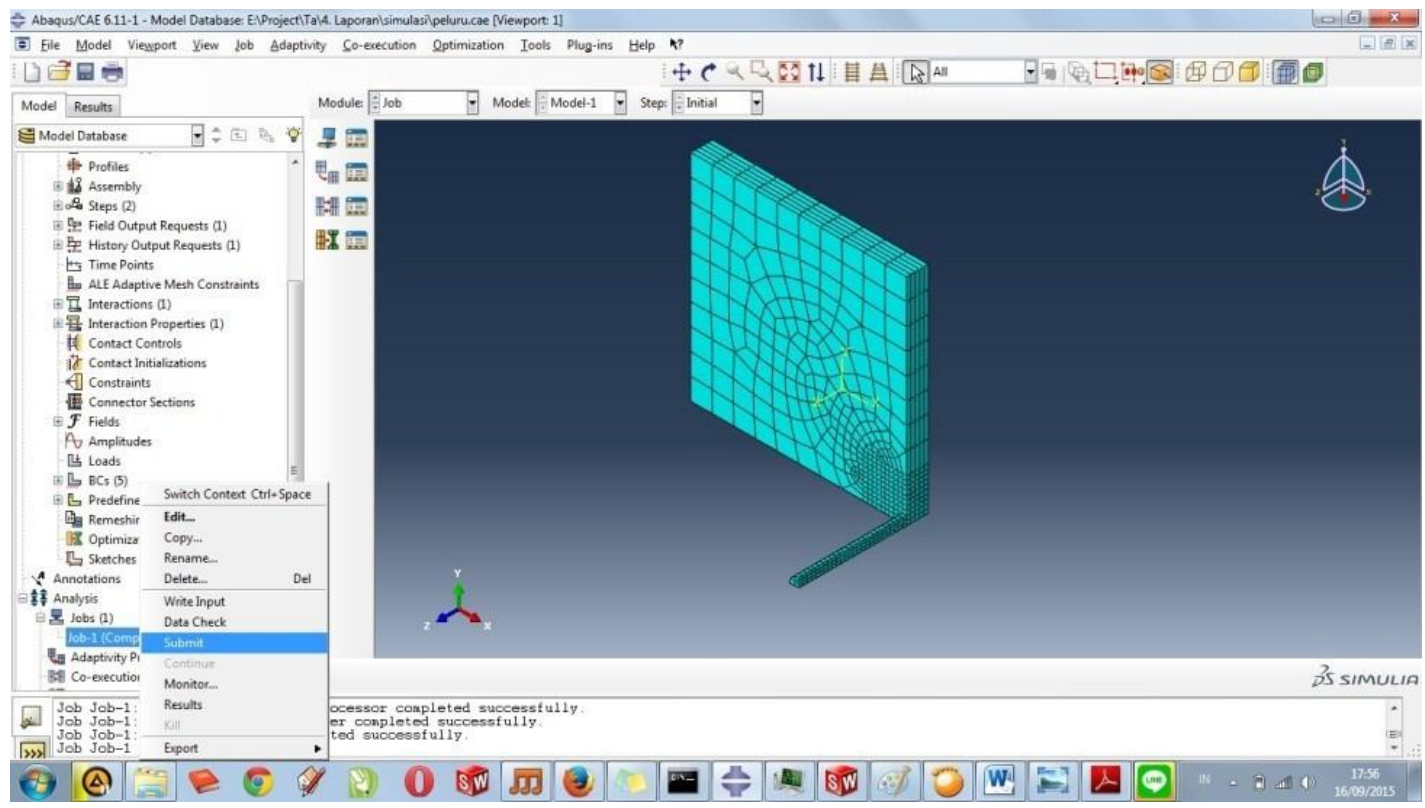

Gambar 7. Assembly plat dengan peluru pada ABAQUS 6.11.

\section{HASIL DAN PEMBAHASAN}

Analisa uji tembak dengan peluru MU4-TJ dilakukan dengan parameter antara lain: peluru MU4-TJ ditembakkan dengan jarak $10 \mathrm{~m}$ pada kecepatan $989 \mathrm{~m} / \mathrm{s}$. Analisa tersebut dilakukan dengan sudut tembak paling kritis yaitu $90^{\circ}$.Tabel 4 menggambarkan hasil simulasi tembak. Gambar 8 menunjukkan tampilan saat peluru MU4-TJ menembus plat baja.

Tabel 4. Hasil simulasi dengan ABAQUS

\begin{tabular}{cccc}
\hline Peluru & Tebal Plat & Stress (MPa) & Keterangan \\
\hline MU4-TJ & $4 \mathrm{~mm}$ & 500.8 & Tembus \\
\hline
\end{tabular}

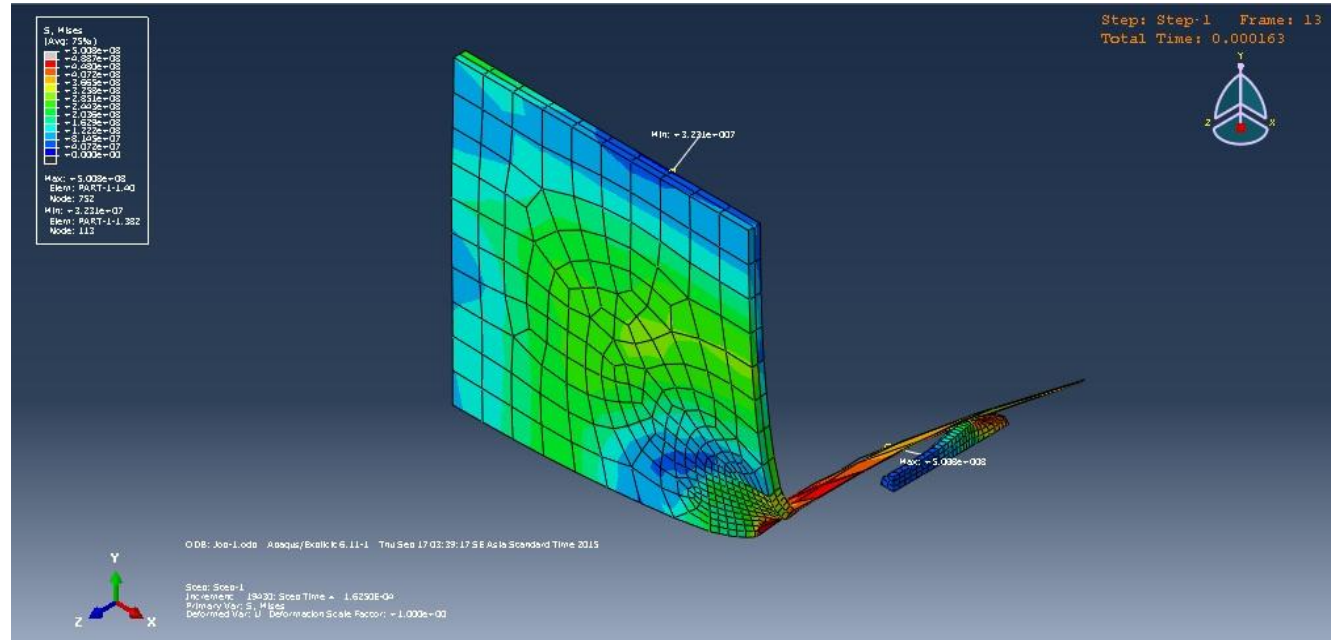

Gambar 8. Tampilan peluru saat menembus plat baja.

\section{KESIMPULAN}

Tegangan yang diperbolehkan harus dibawah nilai Yield Strength dari material penyusun plat yaitu sebesar 470 $\mathrm{N} / \mathrm{mm}^{2}$. Dari 12 titik sampel yang berasal dari amunisi MU4-TJ terdapat 2 titik kritis yaitu munisi MU4-TJ dengan $\sigma=$ $500,8 \mathrm{~N} / \mathrm{mm}^{2}$ pada plat dengan tebal $4 \mathrm{~mm}$ dan $\sigma=498,8 \mathrm{~N} / \mathrm{mm}^{2}$ pada plat dengan tebal $4 \mathrm{~mm}$. Tegangan tersebut terjadi lebih besar dari nilai yield strength artinya penggunaan plat dengan tebal $4 \mathrm{~mm}$ tidak diperbolehkan dan pengaruhnya tidak aman terhadap perancangan. 
Dari hasil analisa software ABAQUS 6.11-1 tebal plat minimal dilihat paling tinggi tegangan von Mises nya dibandingkan yield strength adalah plat dengan tebal $4 \mathrm{~mm}$ dengan munisi MU4-TJ, artinya peluru dengan MU4-TJ adalah peluru dengan ketajaman yang lebih besar dibanding dengan peluru yang lain.

Plat $4 \mathrm{~mm}$ tidak cocok digunakan untuk plat komodo karena seluruh hasil simulasi menunjukkan bahwa plat 4 mm tembus oleh jenis peluru MU4-TJ. Jika plat $4 \mathrm{~mm}$ akan digunakan maka salah satu saran yang dapat diberikan adalah adanya penambahan perlakuan material seperti surface hardening untuk menambah kekuatan material tersebut. Hal ini membutuhkan kajian lebih lanjut.

Hasil ujicoba analisa di atas menggunakan sudut yang paling kritis yaitu sudut $90^{\circ}$, artinya ketika plat tersebut diaplikasikan pada sudut di atas $90^{\circ}$ maka bisa dikatakan lebih aman karena tegangan yang dihasilkan akan semakin kecil dan munisi mengalami recoil (memantul).

\section{REFERENSI}

[1] Pindad. 2014. Kendaraan Tempur Ringan, www.pindad.com, diakses 2 Desember 2014.

[2] Flores-Johnson, E.A. Saleh. M. Edwards. L. 2011. Ballistic Performance of Multi-Layered Metallic Plates Impacted by a 7.62-mm APM2 Projectile. International Journal of Impact Engineering, 38 (12), pp. 1022-2032.

[3] Shanel, V. and Spaniel. M. 2014. Ballistic Impact Experiments and Modelling of Sandwhic Armor for Numerical Simulations. Procedia Engineering, 79, pp. 230-237.

[4] Pindad. 2015. Data Pengujian Balisik Kendaraan Komodo Plat 8 mm. Dokumen Internal. PT. Pindad, Bandung 